\title{
Ideational Grammatical Metaphor in Scientific Texts: A Hallidayan Perspective
}

\author{
Bahram Kazemian (Corresponding author) \\ Department of English, Tabriz Branch, Islamic Azad University, Tabriz, Iran \\ E-mail: Bahram_kazemian@yahoo.com
}

Biook Behnam

Department of English, Tabriz Branch, Islamic Azad University, Tabriz, Iran

E-mail: Behnam_biook@yahoo.com

Naser Ghafoori

Department of English, Tabriz Branch, Islamic Azad University, Tabriz, Iran

E-mail: ghafoori@iaut.ac.ir

Received: August 8, 2013 Accepted: August 19, $2013 \quad$ Published: August 28, 2013

doi:10.5296/ijl.v5i4.4192 URL: http://dx.doi.org/10.5296/ijl.v5i4.4192

\begin{abstract}
Scientific Texts are generally concentrated on highly technical terms, and they are troublesome to understand due to their complexity in forms and meanings. Grammatical metaphor is divided into two broad areas: ideational and interpersonal. This paper focuses on the first type i.e. Ideational Grammatical Metaphor, which includes process types and nominalization. This paper adopts Hallidayan Systemic Functional Grammar to pinpoint and analyze nominalization and the role played by it. With a corpus of 10 authentic scientific texts drawn from very influential magazines, the analysis is conducted based on nominalization, its frequency and process types. The analysis displays that Ideational Grammatical Metaphor has permeated scientific texts and the prevailing process types are material and relational types. Consequently, the tone of the writing is more abstract, technical and formal. Instances of IGM In scientific writing enable technicality and rationality. Based on the findings of this study, some implications can be drawn for academic and scientific
\end{abstract}




\section{Macrothink}

International Journal of Linguistics

ISSN 1948-5425

2013, Vol. 5, No. 4

writing and reading as well as translators, students and instructors involved in writing and reading pedagogy.

Keywords: Systemic functional linguistics, Grammatical metaphor, Ideational grammatical metaphor, Nominalization, Process types, Scientific texts 


\section{Introduction}

The Systemic-Functional Grammar was developed in 1970s by the British linguist M.A.K Halliday, and this particular approach to the study of grammar is significant because it bridges the gap between social and linguistic structure in a precise manner. The basic assumption surrounding Halliday's systemic theory is that form and function of grammar play a fundamental role in discourse formation and that there is a selection of linguistic choices available to satisfy various instances of social needs. Systemic functional linguistics (SFL) is an approach to linguistics that regards language as a social semiotic system. Michael Halliday $(1985,1994)$ took the notion of SFL from his teacher, J R Firth (Graber, 2001; Aronoff \& Miller, 2003).

The theoretical and methodological approach underpinning this work is Grammatical Metaphor (GM) by Halliday (1985, 1994). SFL considers language as a semantic layout of meanings that are generally bound up with a particular context. According to SFL, language thus cannot be separated from either its speakers or its context. The non-congruent ways of encoding language are referred to as GM (Halliday, 1985, 1994; Halliday \& Matthiessen, 1999). Thus, GM is a resource that language utilizes to encapsulate information by conveying concepts in an incongruent form which is very worthwhile in scientific genres as a way of expressing objectification and abstraction. And GM has been of paramount importance in the development of scientific genre, particularly in the form of nominalized processes (Webster, 2005b; Halliday \& Webster, 2009).

Halliday $(1985,1994)$ has categorized GM into Ideational Grammatical metaphor (IGM) and interpersonal Grammatical metaphor, which IGM includes process types and nominalization. Halliday and Webster (2009) have argued about the necessities of nominalization in scientific writing and believe that the urge for it is the fact that the core of scientific texts was the development of a chain of reasoning (ultimately based on experiments) in which each step led on to the next. But directing to the next step, you have to be able to restate what has formerly mentioned and to put in their term, is now being used as a springboard for the next move.

They also assert that all human adults and all languages are endowed with this ability to move from the clausal to the nominal construal of experience, but this inherent potential in the grammar, which enables us to de-couple the lexico-grammatical interface and to re-couple it with a different ordering, is the most quality of scientific genre and the need to construct technical terms and sequential argument (Halliday \& Webster, 2009). Surveys conducted by Halliday and Martin (1993) have shown that in certain types of discourses, such as scientific discourses, nominalizations feature frequently. It is commonly known that complexity in scientific language is achieved mainly through specific terminology and nominalization, which is part of GM. Thus, the main manifestation of the IGM is nominalization. Noun is the most common GM in the word level, it makes the verb which expresses the process and the adjective which expresses the quality lose functions of their own, so that they can demonstrate something in the form of a noun. 


\section{Review of Literature}

Studies related to GM have grown rapidly in number since the introduction of the concept in Halliday's first edition of his Introduction to Functional Grammar (1985). Moreover, the interest in the use of GM in specialized language use seems to have increased after Halliday's and Martin's (1993) analysis of the use of GM in technical and scientific writing.

Halliday's systemic theory of grammar is based on the idea that language is governed by simultaneous functions. In SFG, the context of situation is built into the grammatical analysis of a clause. The link between the grammatical form of language and the situation is made possible by a hypothesis, a metafunctional hypothesis, about the relationship between them. A metafunctional hypothesis is not a hypothesis about the functions or uses of text, as reflected in functional theories of language, but a hypothesis about the internal grammatical organization of the clause, about those functions of language that are built into the very structure and organization of language itself (Halliday \& Matthiessen, 2004; Taverniers, 2006; Caffarel, 2006).

These functions of language can be seen as generalized types of meaning, which are realized in the lexico-grammatical form of a language. There are three basic components which construct meaning in language- ideational, interpersonal and textual components. The ideational component is to do with experiences and happenings in the outside world. The ideational function enables people to construe reality by configuring their experiences into clauses. The second component is about the relationship established between people who are engaged in a particular discursive setting. Lastly, in the textual component, the thematic structure is observed, indicating a focal point of the message to identify what the clause is about (Rose, 1997; Graber, 2001; Webster, 2005a).

GMs can be identified in terms of the metafunctions. "GM is a substitution of one grammatical class, or one grammatical structure, by another" Halliday and Martin (1993, p. 79); for example, his reflection on instead of he reflected on. Simply put, the process of reflecting has been turned into a noun. Or this ambivalence towards literacy would be the metaphorical form of the congruent correspondent people are ambivalent toward literacy (Taverniers, 2003). The grammar encapsulates what has gone before, the preceding step in the experiment, by nominalizing the process or quality which should be expressed by the verbs and adjectives, for instance:

\subsection{The Inflation needs to be curbed; but the curb must be based on systemic measures.}

In the above instance, the Process - to curb - is nominalized into a noun - the curb. In the following example (a), not only have the processes (affect, delay and transmit) been nominalized, but also has an adjective (cyclic).

a. even minor delays in the parasite's life cycle can have important effects on transmission rates.

b. If the cyclic life of parasite is delayed for a short time, it can chiefly affect the rate to transmit. 


\section{Al Macrothink}

International Journal of Linguistics

ISSN 1948-5425

2013, Vol. 5, No. 4

Halliday $(1985,1994)$ considers that there are two kinds of expressions: congruent, or non-metaphorical; and incongruent or metaphorical. In general, it is considered that people, places and things are realized by means of a noun; actions are realized verbally, and so on. As aforementioned, he considers two types of GMs, the Ideational, (IGM), in which it includes process types and nominalization, and the Interpersonal one.

Nominalization constructs long noun phrases to generate informationally dense constructions and this is the reason why most scientific genre is intricate to grasp. Among the particular grammatical characteristics of scientific writing argued by Halliday and Martin (1993) is the nominalization of processes. IGMs are the metaphors of transitivity. To pinpoint the metaphorical nature of a non-congruent expression, it is essential to compare it with an equivalent congruent realization (Halliday \& Martin, 1993; Knowles \& Moon, 2006).

Transitivity choices involve selections from various process types that are realized in verbal groups; the associated participant roles are realized in nominal groups and the circumstances are realized in either prepositional phrases or adverbial groups as follows (Cehan, 2004; Webster, 2005a). Process types may be material (a), mental (b), behavioral (c), verbal (d), relational (e) or existential (f):

a. We fixed the motorcycle.

b. Just reflect on it.

c. She composed a letter to the local paper.

d. State your idea about the issue.

e. Azerbaijan is a beautiful province.

f. There is someone waiting for you outside.

Halliday $(1985,1994)$ views transitivity as an ideational feature which serves to linguistically construct the goings-on of the real world. According to his theory of SFL, transitivity configures linguistic elements to represent inner and outer experiences of the world:

Table 1. Process Types in English

\begin{tabular}{|c|c|c|}
\hline Process types & $\begin{array}{l}\text { Category } \\
\text { meanings }\end{array}$ & Example \\
\hline $\begin{array}{l}\text { Material : } \\
\text { Action }\end{array}$ & $\begin{array}{l}\text { 'doing' } \\
\text { 'doing' }\end{array}$ & $\begin{array}{l}\text { The monarch had the power to dissolve } \\
\text { the parliament. }\end{array}$ \\
\hline Event & 'happening' & The communists were ousted from power. \\
\hline Behavioral : & 'behaving' & She shrieked in agony. \\
\hline $\begin{array}{l}\text { Mental: } \\
\text { Perception } \\
\text { Affection } \\
\text { Cognition }\end{array}$ & $\begin{array}{l}\text { 'feeling' } \\
\text { 'sensing', } \\
\text { 'emotive' } \\
\text { 'thinking' }\end{array}$ & $\begin{array}{l}\text { I heard a noise outside. } \\
\text { The boy loved the girl. } \\
\text { You can visualize meeting her again. }\end{array}$ \\
\hline
\end{tabular}




\begin{tabular}{|c|c|c|}
\hline Verbal: & 'saying' & $\begin{array}{c}\text { Police described the attack as } \\
\text { particularly violent. }\end{array}$ \\
\hline Relational: & 'being' & This milk is sour. \\
Attribution & 'attributing' & Jen is her brother. \\
Identification & 'identifying' & Maybe there's some other darker pattern. \\
\hline Existential: & 'existing' &
\end{tabular}

The above table represents the process types in English with category meanings and examples adopted from Martin, Matthiessen, and Painter (1997, p. 228).

\subsection{GM and Scientific Discourse}

The language of science is, by its essence, a language in which theories are built and its features are definitely those that make theoretical discourse potential. There are two types of resources in Scientific language: lexical and grammatical. Lexical ones include technical terminologies that scientific realm continuously construct i.e. technicality. Grammatical resources include constructing organized nominal categories so that they can be merged to construe a particular form of reasoning and sequential argument. Scientific genre is a highly nominalized discourse. Nominalization is indispensible since it is engaged both in technicality and rationality. Thus, the difference between grammatical and lexical metaphors is that in GMs the lexical item does not change in meaning but in function, for example: we consider = our consideration. In the lexical metaphor the lexical item changes in meaning and there is a non-literal use of words (Vandenbergen, Marie, Taverniers \& Ravelli, 2003; Webster, 2005b; Taverniers, 2006).

Linguistically speaking, there are two views regarding metaphor i.e. view from below and view from above. Traditionally, metaphor is viewed as variation in the use of words, i.e. variation in meanings; this is a view from below (lexical), taking the words as starting point and then saying something about the meanings these words realize. Metaphor is, however, employed in SFL in a relatively new sense to refer not to the variation in the use of words with a transferred meaning but to variation in the expression of meaning. Taking this from above view, it is acknowledged that metaphoricity is lexico-grammatical rather than merely lexical, and that lexical choice is just one feature of lexico-grammatical selection; the other dimension is grammatical (Halliday, 1985, 1994; Taverniers, 2006, 2002).

Webster $(2003,2005$ b) maintain that modern scientific and technical knowledge not only was first evolved but also is still being extended through the nominalizing metaphoric grammar, in which processes, and the qualities and properties both of process and things, are reconstructed as if they were things: to transplant stem cell became stem cell transplantation and to prevent and control disease became disease control and prevention. Now there is a strong reason for thinking that this metaphorical reconstrual of experience in the grammar was a necessary step towards a more powerful understanding - towards theorizing that experience in what we would now call scientific terms. GM- the decoupling and re-coupling of grammar and semantics- made scientific theory possible.

To explain about the necessity of using nominalization as the chief type of experiential GM 
in scientific discourse, Halliday and Matthiessen (2004), as mentioned before, regard two semiotic conditions which are required to be met in scientific theory; technicality and rationality. To justify the first condition, it is pointed out that the grammar has to create technical meanings, purely virtual phenomena that exist only on the semiotic plane. They, then, assert that nominal group is the most powerful resource helping manage the complexity being inherent in the scientific discourse. Rationality in science, as they argue, is observed when the discourse needs to construct an argument out of a long sequence of connected steps and the previous steps may be organized as grounds for the next. Once discourse is in motion, the Theme will typically pick up something that has gone before (Halliday \& Matthiessen, 2004).

It has been argued that the development and evolution of nominalization probably began in scientific and technical genres and then gradually spread to other realms of adult discourse and become a sign of prestige and power. Thus, GM has been of particular importance in the evolution of scientific writing, especially in the form of nominalized processes (Halliday, 1985, 1994; Webster, 2005b; Halliday \& Webster, 2009). In surveys and studies related to GM in scientific genre (Halliday \& Martin, 1993; Vandenbergen, et al, 2003), it implies that there are some particular characteristics and reasons why scientific discourse requires nominalization such as abstraction, objectivity, condensation, information density, technicality, and reasoning each of which will be spelled out as follows:

\subsubsection{Objectivity}

Developed mainly by Halliday $(1985,1994)$, the concept of GM depicts an original and pioneering contribution that determines and elaborates the fact that scientific and academic discourses, in writing and in speaking, are practically intended to achieving objectification and abstraction of their content. They accomplish this functional goal through the linguistic resource of GM, a means that packs information by stating experiences and events in a metaphoric form, as contrasted with the more ordinary non-metaphoric form that prevails in everyday language use. Nominalizations produce a greater concentration of the experiential meaning and a smaller incidence of interpersonal elements, such as personal pronouns and modal verbs, thus presenting information in a less personalized way, e.g.

a. Researchers in the College of Agricultural Sciences are making progress in pinning down the cause or causes of colony collapse disorder, a mysterious ailment that threatens the beekeeping industry and the crops and native plants that rely on honey bees for pollination. (GM)

b. Researchers in the College of Agricultural Sciences are progressing to pin down what has caused a colony to be collapsed and disordered, it is a mysterious ailing that threatens the industry to keep bees and the crops and native plants that rely on honey bees to get pollinated. (Congruent)

Unlike the commonsense language used for construing everyday life experiences, scientific language theorizes concrete life experiences into abstract entities, which can then be further examined and critiqued. Such theorizing involves turning processes into nouns, as the above 
example (a). One reason why nominalization is in harmony with the ideology of scientific, academic, and formal writing in general, is that it makes it easy for processes to be objectified- to be expressed without the human doer.

\subsubsection{Condensation}

Nominalizations decrease longer phrasal compounds and structures in scientific registers, making it more packed, more practical, pragmatic and direct to the experts. This can be done by concise referring to aforementioned concepts in the texts and summary. They sum up the contents of a previous discussion before introducing new information. By nominalizing, processes, and qualities can include a large amount of information in a comparatively small place by encapsulating a large number of lexical items into one clause. Thus, packing is of paramount importance in scientific genre, e.g. 128,000 hospitalizations instead of 128,000 have been hospitalized (Thompson, 2004; Eggins, 1994).

\subsubsection{Information Density}

As pointed out by Halliday $(1985,1994,1989)$, GM tends to occur much more frequently in written language and in adult speech. GM is one of the factors which contribute to the higher degree of lexical density in written English. Thus, According to Halliday and Martin (1993, p. 21), "lexical density is a measure of the density of information in any passage of text", according to how firmly the lexical terms have been compacted into the grammatical structure, e.g.

It is seen as an aberration perpetrated by irresponsible and criminal elements, motivated by greed or excitement, the dupes of political extremists, or imitating the behavior of others.

Motivated by greed or excitement... is a compound GM and lexical density is apparent there. The writer couldn't possibly and apparently express and capture his intended meaning through the congruent domain using the phrase: by those who are greedy and those who are excited, and those who are duped by..., so he brings in the metaphorical form for ease of transmitting the intended message to the readers and makes it impressive, vivid and intriguing for them to digest it. The role of GM is very essential here in the way that it is put and is fixed into the mind of the readers. Thus, texts in which there are great numbers of nominalizations can be very complex and dense because information can be encapsulated and it may be intricate to process. It is worthy noting that grammatical simplification and lexical density run concurrently in parallel with, which refers to the fact that the fewer clauses are going to accommodate the lexical items. Nominalization boosts the density of the materials in any texts and enhances the content of phrases through packing the sentences into a noun or noun phrase (Eggins, 1994; Halliday \& Matthiessen, 1999).

\subsubsection{Technicality \& Rationality}

As mentioned earlier, GM in scientific texts enables technicalizing and rationalizing and theses processes are dependent on the clausal to nominal shift which most strongly characterizes GM. Technicality by itself would be of low worth unless accompanied by rationality. These functions of nominalization are particularly practical in scientific discourse. 


\section{Al Macrothink}

International Journal of Linguistics

ISSN 1948-5425

2013, Vol. 5, No. 4

Primarily, they make it possible to construct technical terminologies and, secondly, once a process is nominalized, it can easily be adapted and associated with other processes, which enables the scientist to advance considerably his or her discussion by utilizing complex passages compacted into nominal groups (Vandenbergen et al., 2003).

Consequently, scientific discourse has to create technical meanings and technical terms due to new inventions, discoveries etc. such as bioinformation, psychobioinformation, Chlorination, blastomycosis, Salmonella and Shigella infections and so on. These are nominalizations, encapsulated concepts which were established clauselly in some parts of the texts of this study or some other texts. The reasoning emerges at this point in any scientific texts to elucidate and elaborate on the freshly minted words and/or intricate terms.

All the above mentioned properties, as Halliday and Martin (1993) argue, are direct results of GM. To identify the distinctive characteristics scientific English possesses and what functions they have in the discourse, Vandenbergen et al. (2003) believe that although technical terms are part of this overall effect, the difficulty lies more with the grammar than with the vocabulary. The problems with technical terminology usually arise not from the technical terms themselves but from the complex relationship they have with one another.

Halliday and Martin (1993) also suggested seven headings which can be used to illuminate the features of scientific English in which some of them are discussed earlier: (1) interlocking definitions, (2) technical taxonomies, (3) special expressions, (4) lexical density, (5) syntactic ambiguity, (6) grammatical metaphor (GM), (7) semantic discontinuity. In scientific writing, the lexical density (4) may go much higher and the language appears intricate because it contains a significant number of interrelated technical taxonomies and each of which has been defined and includes information the reader is expected to already make sense of and scientific language has developed to enable scientists to have effective communication. Among these features, they regard GM more significant because they state that the items (4) and (5), mentioned above, are both by-products of GM (Halliday \& Martin, 1993; Vandenbergen et al., 2003).

Halliday and Matthiessen (1999, pp. 246-248) further categorize GM into thirteen types of elemental transference, some of which will be illustrated as follows. It is clear that a great deal more is happening at the rank of word than simply construing processes and qualities as entities. The GM involves a complex move down in rank and across in function. However, first, there is a need to clarify the possible range of metaphoric transition from semantic function to grammatical class. Some of the metaphoric shifts which may be found in scientific genre are listed in Table 2 as follows: 
Table 2. Samples and types of GM

\begin{tabular}{|c|c|c|c|}
\hline \multicolumn{2}{|c|}{ Shift in semantic type } & \multicolumn{2}{|c|}{ Shift in grammatical class } \\
\hline Congruent & metaphorical & Congruent & phorical \\
\hline 1. quality & entity & 1. Adjective & noun \\
\hline 2. process & entity & 2. Verb & un \\
\hline 3. process & quality & 3. Verb & ective \\
\hline 4. circumstance & quality [manner] & 4. Adverb & ljective \\
\hline & quality [time] & 5. Adverb or & \\
\hline & quality [place] & prepositional phrase & adjective \\
\hline 5. relator & entity & & \\
\hline 6. relator & quality & 6. Prepositional phrase & noun premodifier \\
\hline 7. relator & process & 7. Conjunction & noun \\
\hline 8. relator & circumstance & 8. Conjunction & adjective \\
\hline 9. entity & modifier of) entity & 9. Conjunction & verb \\
\hline
\end{tabular}

The following, which are taken from examples 1 to 9 given above, depicts the shifts outlined in Table 2, extracted from scientific texts of this study:

1. Abundant $\longrightarrow \quad$ abundance

2. Pollinate $\longrightarrow$ pollination

3. When he is hyperventilating his lungs $\longrightarrow \quad$ hyperventilating his lungs

4. May be motivated increasingly $\longrightarrow \quad$ increased motivation [manner]

$$
\begin{array}{lr}
\text { transform simultaneously } \longrightarrow & \text { simultaneous transformations [time] } \\
\text { hydroxyl groups on the surface } \longrightarrow & \text { surface hydroxyl groups [place] }
\end{array}
$$

5. After introducing the virus, we observed dramatic bee mortality increased $\longrightarrow \quad$ The result of introducing the virus was increasing dramatic bee mortality

6. After introducing the virus, we observed dramatic bee mortatity increased The resultant increasing dramatic bee mortality was due to introducing the virus

7. After introducing the virus, we observed dramatic bee mortatity increased Increasing dramatic bee mortality resulted from introducing the virus

8. After introducing the virus, we observed dramatic bee mortatit increased bee mortality increased as a result of introducing the virus

9. Drug resists - drug resistance.

For example, the metaphoric transformation of abundant to abundance would display a shift from construed as a quality to construed as an entity, from adjective into noun, e.g. for orchid fungi which is abundant .... for orchid fungi abundance.

From what it has discussed, two considerations can be made: (a) in metaphoric transition 
there is a general tendency towards thingness. The direction of metaphor in a move towards the concrete and the noun is the most metaphorically attractive category; (b) there is a relation between the two dimensions of the metaphorical domain: the shift in rank and the shift in class. (Halliday \& Matthiessen, 1999). As a consequent, the types of metaphor are organized in terms of the metafunctional effect of the metaphor. Generally as depicted above, there are four major groupings of IGM: (a) Shift to thing, (b) shift to quality, (c) shift to process, (d) shift to circumstance. Within each of these main groups, there are a number of sub-groups as well.

\subsection{Research Questions and Hypotheses}

Based on the main purpose of the research and the scope of the study, the researchers would try to find logical answers to the following research questions.

1. Are there any IGMs embodied in these scientific texts and what are their respective frequencies and percentage?

2. If such frequencies exist, how are they realized in terms of process types?

And the following hypotheses, accordingly, were formulated,

1. There are a large number of IGMs in scientific texts.

2. There are a small number of IGMs in scientific texts.

\section{Methodology}

\subsection{Corpus}

Due to the foremost importance of choosing authentic and native texts in scientific genres, an effort was made to choose scientific texts from various sources such as Scientific American Magazine (2012), and some on-line magazines titled Atlantis Rising Magazine (2012), Penn State Ag Science (2010, 2011), Penn State Agriculture Magazine (2008).

Because of time constraints, only 10 scientific, approximately 6100 words, were used as the corpus in order to pinpoint and analyze the frequency of nominalizations and also to find their relevant process types. It should be noted that almost all selected texts from the aforementioned sources amount to roughly the same numbers (about 600 words per text). All texts should comprise the same number of words to be investigated appropriately. Thus, it is the same number of words that acts as our yardstick and can able the researchers to say, for instance, how many instances of GM are used and which process type is dominant in all texts.

\subsection{Procedure}

In order to pinpoint IGMs in these texts and to render them in congruent domain to identify their process types, it was necessary to select a model or models to analyze the data. Therefore, the ideas of Halliday (1985, 1994), Halliday and Matthiessen (1999) and Martin et al. (1997) as the most comprehensive ones were utilized as the main theoretical foundation of the present research. As argued above, underlying elements to transitivity system are processes which are realized by the verbal group and by nominalization, in which a semantic 
category such as a process is realized by a typical grammatical class such as a noun, instead of a verb. Processes are also regarded as what goings-on and suggest many different kinds of goings-on which necessarily involve different kinds of participant in varying circumstances, while participants and circumstances are fundamental upon doings, happenings, feeling and beings. Processes can be subdivided into different types. There are six various types identified by Halliday $(1985,1994)$ :

1) Material (doing), 2) Mental (sensing), 3) Relational (being), 4) Verbal (saying), 5) Behavioral (behaving), and 6) Existential (existing).

To identify the instances of IGM in the scientific texts, the researchers read the texts thoroughly and discovered IGMs. It was noticed that nominalization is the most dominant feature of scientific texts that leads to IGM. After establishing and extracting IGMs, an effort was made to render metaphorical expressions in congruent expressions, because according to Halliday (1985, 1994), each metaphorical wording must have its equivalent congruent wording. Thus, in this research not only process types but also congruent domains of extracted IGM instances were discussed and it is believed that elaborating both the congruent and metaphorical domains lead us to fully grasp the concept of transitivity system.

It is worth noting that unpacking metaphorical wordings into congruent forms are based on inventories represented by Eggins (1994), Halliday (1985), Halliday and Matthiessen (1999), Martin et al (1997), and Thompson (2004). Comparing metaphorical and congruent wording indicated that in most of the cases both of them allow us to explain the same situation, but the metaphorical wording describes the situation in a more encapsulated, brief, precise and concise way. Since IGM is closely tied with transitivity system which enables us to construe the world of our experience into a limited set of process types, an attempt was made to identify process types in all the extracted and rendered IGM instances. It is noticed that some metaphorical words are frequently used in each texts. Thus, the frequency of each metaphorical word in each text was scored separately. Tables were drawn based on metaphorical and congruent expressions, a certain type of process as well as frequency and percentage of process types in per text.

\subsection{Design}

The design of the present study was descriptive-analytic which concentrated on the frequency of occurrences of IGM and their congruent wording in scientific texts. As a model of analysis, Hallidyan SFL's model of text analysis is utilized as a yardstick to analyze the process types of clauses.

\section{Data Analysis}

\subsection{Introduction}

The principal objective of the present study is to enquire into IGM and their respective frequencies and also to identify and analyze the related process types in the corpus comprising 10 scientific texts, approximately 6100 words. These texts were analyzed in order to see how many instances of IGM are used in them and what the respective frequencies are. 
Furthermore, the data has been investigated to find out the role and function of IGM in terms of process types.

\subsection{IGM in Scientific Texts}

Halliday and Martin (1993) argue several ways in which meaning is encapsulated in scientific discourse. One way is by the utilization of technical terms, which pack information on the content plane. Another way of condensing meaning frequently used in science discourse is by means of GMs such as nominalization. They also highlight that, as mentioned before, scientific texts are found to be complex to read; and this is so, because they are written in scientific language, a jargon which has the effect of making the learner to be firmly distanced and excluded from the subject matter. They stress that it is not only ESL students who find problems with scientific English but also do many for whom English is the mother tongue. To identify the distinctive features scientific English possesses and what functions they have in the discourse, Halliday and Martin (1993) and Vandenbergen et al. (2003) believe that although technical terms are part of this overall effect, the complexity lies more with the grammar than with the vocabulary.

A considerable amount of literature and several attempts have been undertaken to investigate and analyze GM and IGM in other discourses as well as scientific discourse (Halliday \& Matthiessen, 1999, 2004; Halliday \& Martin, 1993; Webster, 2003, 2005a, b). These studies have demonstrated the use of GM in scientific register and have revealed that scientific register is frequented by instances of GM. It has been claimed that, despite its abstractness, GM functions to construct technicality and facilitate the development of reasoning by summarizing the preceding arguments. Thus, Nominalizations are the chief conveyor of concepts and information in academic scientific writing. They communicate very specialized and precise knowledge to the audience who must share with the writer the required level of knowledge of the subject discipline. The more technical and specialized the subject, the more frequent the nominalization and the more complicated the texts.

Table 3. Samples of IGMs in Scientific Texts from texts 1, 2, 3, 4 and 5 of the study.

\begin{tabular}{|c|c|c|c|c|}
\hline No. & Metaphorical wording & Congruent wording & $\begin{array}{c}\text { Process } \\
\text { type }\end{array}$ & $\begin{array}{c}\text { Frequency } \\
\text { in per text }\end{array}$ \\
\hline $\mathbf{1}$ & or in combination with & or to combine with them & material & $\mathbf{1}$ \\
\hline $\mathbf{2}$ & these exotic-looking flowers & $\begin{array}{c}\text { these flowers which look } \\
\text { exotic }\end{array}$ & relational & $\mathbf{1}$ \\
\hline $\mathbf{3}$ & in addition to their beauty & $\begin{array}{c}\text { in addition that they are } \\
\text { beautiful }\end{array}$ & relational & $\mathbf{1}$ \\
\hline $\mathbf{4}$ & the existing fungi & fungi which exists & existential & $\mathbf{1}$ \\
\hline $\mathbf{5}$ & promote growth in each & $\begin{array}{c}\text { each orchid will be } \\
\text { promoted to grow more }\end{array}$ & material & $\mathbf{1}$ \\
\hline $\mathbf{6}$ & $\begin{array}{c}\text { along with the beating of our } \\
\text { heart }\end{array}$ & $\begin{array}{c}\text { when our heart beats and it } \\
\text { is accompanied by }\end{array}$ & material & $\mathbf{1}$ \\
\hline $\mathbf{7}$ & when preventing water or & when it prevents water or ... & material & $\mathbf{1}$ \\
\hline
\end{tabular}




\begin{tabular}{|c|c|c|c|c|}
\hline & dust & & & \\
\hline 8 & when stabilizing our chests & when it stabilizes our chest & material & 1 \\
\hline 9 & after inflating our lungs & after that we inflate our... & material & 1 \\
\hline 10 & $\begin{array}{l}\text { to explain the one-minute } \\
\text { limit }\end{array}$ & $\begin{array}{l}\text { to explain a situation that is } \\
\text { limited for one minute }\end{array}$ & material & 1 \\
\hline 11 & by becoming more and more & to become more and more & relational & 1 \\
\hline 12 & with limited success & to succeed with limitation & material & 1 \\
\hline 13 & $\begin{array}{l}\text { engaged in this great } \\
\text { adventure }\end{array}$ & $\begin{array}{l}\text { engaged in a greatly } \\
\text { adventurous action }\end{array}$ & relational & 1 \\
\hline 14 & with a lack of curiosity, & $\begin{array}{l}\text { to lack to be curious and to } \\
\text { be educated }\end{array}$ & relational & 3 \\
\hline 15 & $\begin{array}{c}\text { they make distinctions } \\
\text { between }\end{array}$ & they distinguish between & mental & 1 \\
\hline 16 & $\begin{array}{l}\text { there may be lifelong } \\
\text { consequences }\end{array}$ & $\begin{array}{l}\text { it may have lifelong } \\
\text { consequent effects }\end{array}$ & relational & 1 \\
\hline 17 & from toddlerhood that & when she used to toddle and & material & 1 \\
\hline 18 & surveillance project & the project is surveillant & relational & 2 \\
\hline 19 & could be a coincidence & it could coincide with & material & 1 \\
\hline 20 & comprehensive analyses & to analyze comprehensively & mental & 1 \\
\hline 21 & to their antiquity & that they are antique & relational & 2 \\
\hline 22 & $\begin{array}{l}\text { the greatness that was to be } \\
\text { Rome }\end{array}$ & $\begin{array}{l}\text { that Rome was to be very } \\
\text { great }\end{array}$ & relational & 1 \\
\hline 23 & $\begin{array}{c}\text { with the ongoing political } \\
\text { instability in Egypt }\end{array}$ & Egypt is politically instable & relational & 1 \\
\hline 24 & the destruction of some of & to destroy some of & material & 1 \\
\hline 25 & action against them & to act against them & material & 2 \\
\hline
\end{tabular}

Out of 301 nominalizations in Texts 1, 2, 3, 4 and 5, 134 go for material, 99 for relational, 19 for mental, 23 for verbal, 22 for behavioral and 4 for existential processes. By comparing the congruent and metaphoric versions in above instances, it implies that unpacking a text often involves re-inserting human actors, often rendered unnecessary by nominalization. When we simply compare the length of the original nominalized text with the length of the unpacked version, the ability of nominalization to compact meanings is obvious. Remarkably, this non-metaphorical version has lost much of its reputable sound (Eggins, 1994). In All texts of this study, nominalization has also utilized to introduce a topic that the writer has developed in the next few sentences or expanded and elaborated in the previous sentences. Thus, Nominalizations can facilitate smooth conveyances between clauses by serving as subjects that refer back to ideas in previous clauses or next clauses as follows:

4.2.1 The blue strands in this image of a mouse testis provide evidence that transplanted stem cells regenerated sperm production and restored fertility to a previously infertile mouse. The blue coloration results from a trait of the transgenic donor mouse, which has a special gene that turns his cells blue under special treatment. The echnique of testicular stem cell 
transplantation holds promise for men who have become infertile due to treatment for cancer and other diseases. Current practice has men store semen for possible in vitro fertilization later, an expensive and not always reliable technique. Translating the mouse techniques to humans may provide a means to reestablish natural fertility by harvesting stems cells before treatment and reinserting them later, after the harmful effects of the cancer therapy have subsided (adopted from Penn State Ag science magazine).

Nominalization can increase the information load of the nominal group, and it succeeds in condensing the information of the clause. Nominalization allows series of argument and discussion, to be reiterated in summary form -packed, as it were, and compacted by the grammar- so that it serves as the beginning for a further step(s) in the rationality and sequential argument (Vandenbergen et al., 2003; Murar, 2004). In the above example, all the properties and functions of scientific texts suggested by Halliday and Martin (1993) such as lexical density, syntactic ambiguity, GM, technicality and rationality are apparent. There are 16 nominalizations such as fertility, treatment, transplantation and fertilization etc. in the text. Technical taxonomies such as testis, transplant, coloration, transgenic and fertility are utilized through the text. The author has made an effort to illustrate and explain those technical terms by reasoning, expanding the topic and GM as well. The more GMs in the text, the fewer processes, and consequently, the more information load and lexical density will be. It should bear in mind that scientific writing has a particular tendency for nouns, especially the extended and nominalized ones. According to Halliday and Martin (1993, p. 8), the development of scientific language has been one that "foregrounds participants and backgrounds actions and processes". The following samples of IGMs of this study are selected haphazardly from texts $6,7,8,9$, and 10 as follows:

Table 4. Samples of IGMs in Scientific Texts from texts 6, 7, 8, 9 and 10 of the study.

\begin{tabular}{|c|c|c|c|c|}
\hline No. & Metaphorical wording & Congruent wording & $\begin{array}{c}\text { Process } \\
\text { type }\end{array}$ & $\begin{array}{c}\text { Frequency } \\
\text { in per text }\end{array}$ \\
\hline $\mathbf{1}$ & our imaginings & we have imagined it & mental & $\mathbf{1}$ \\
\hline $\mathbf{2}$ & and resembling our own & and it resembles our ... & relational & $\mathbf{1}$ \\
\hline $\mathbf{3}$ & the density of the air & the air is dense and ... & relational & $\mathbf{1}$ \\
\hline $\mathbf{4}$ & amazing coincidence & to coincide amazingly & material & $\mathbf{1}$ \\
\hline $\mathbf{5}$ & seasonal color changes & how seasonal color are & material & $\mathbf{1}$ \\
\hline $\mathbf{6}$ & to our understanding of the & for us to understand the ... & mental & $\mathbf{3}$ \\
\hline $\mathbf{7}$ & It will be the end of & it will end ... & material & $\mathbf{2}$ \\
\hline $\mathbf{8}$ & and spirituality & an to be spiritual & relational & $\mathbf{1}$ \\
\hline $\mathbf{9}$ & physical manifestation of a & to manifest physically a & behavioral & $\mathbf{1}$ \\
\hline $\mathbf{1 0}$ & absoluteness of space & the space is absolute & relational & $\mathbf{1}$ \\
\hline $\mathbf{1 1}$ & colony collapse disorder & colony which is collapsed & material & $\mathbf{3}$ \\
& & and disordered & material & $\mathbf{3}$ \\
\hline $\mathbf{1 2}$ & that threatens the beekeeping & $\begin{array}{c}\text { that threatens the industry to } \\
\text { keep bees }\end{array}$ & material & $\mathbf{2}$ \\
\hline
\end{tabular}




\begin{tabular}{|c|c|c|c|c|}
\hline $\mathbf{1 3}$ & for pollination & to be pollinated & material & $\mathbf{1}$ \\
\hline $\mathbf{1 4}$ & $\begin{array}{c}\text { the presence of dozens of } \\
\text { chemicals }\end{array}$ & $\begin{array}{c}\text { that dozens of chemicals are } \\
\text { present }\end{array}$ & relational & $\mathbf{1}$ \\
\hline $\mathbf{1 5}$ & killing the parasite & how to kill the parasite & material & $\mathbf{2}$ \\
\hline $\mathbf{1 6}$ & $\begin{array}{c}\text { 30 percent of the world's } \\
\text { malaria infections }\end{array}$ & $\begin{array}{c}\text { 30 percent of people who } \\
\text { are infected by malaria in ... }\end{array}$ & material & $\mathbf{1}$ \\
\hline $\mathbf{1 7}$ & $\begin{array}{c}\text { requires a different treatment } \\
\text { requires to be treated } \\
\text { differently }\end{array}$ & material & $\mathbf{1}$ \\
\hline $\mathbf{1 9}$ & with an accurate diagnosis & and diagnose it accurately & mental & $\mathbf{1}$ \\
\hline $\mathbf{2 0}$ & $\begin{array}{c}\text { we need a balance of } \\
\text { allowing a }\end{array}$ & $\begin{array}{c}\text { we need to balance it and } \\
\text { allow a mosquito ... }\end{array}$ & $\begin{array}{c}\text { material } \\
\text { relational }\end{array}$ & $\mathbf{2}$ \\
\hline $\mathbf{2 1}$ & population dominated & $\begin{array}{c}\text { you have mosquitoes that } \\
\text { are populated and } \\
\text { susceptibility to breast }\end{array}$ & material & $\mathbf{1}$ \\
\hline $\mathbf{2 2}$ & sperm production and & that they are susceptible \\
to ... & relational & $\mathbf{1}$ \\
\hline $\mathbf{2 3}$ & $\begin{array}{c}\text { for possible in vitro } \\
\text { fertilization }\end{array}$ & $\begin{array}{c}\text { to be possibly fertilized in } \\
\text { vitro }\end{array}$ & material & $\mathbf{1}$ \\
\hline $\mathbf{2 4}$ & stem cell activity in the \\
testes & how the stem cell acts in the \\
testes & material & $\mathbf{1}$ \\
\hline
\end{tabular}

Webster (2005a, b) drew our attention to the fact that there are also some practical reasons for analyzing scientific texts. The most obvious is educational: students of all ages may find scientific texts intricate to read and it is known from various research reports that, in English at least, the difficulty is largely a grammatical one. Thus doing something about it, we have to grasp how the language of these texts is constructed. Of course, if a text is hard to read the complexity is bound to be in some sense linguistic, since texts consist entirely of language, but in the case of scientific writing it seems that there are certain characteristics of the way meanings are organized, and the way they are worded, that present special problems for a learner, over and above unfamiliar subject matter and its alienation from everyday experience. So people recognize that there is such a thing as scientific language, at least in the written mode.

In these five texts $(6,7,8,9$ and 10), out of 257 process types, 146 processes are material, 82 are relational, 12 are mental, 14 are verbal, 3 are behavioral and none is existential. In the above Tables $(3 \& 4)$, there are many processes rendered in nouns, that is, abstract entities such as our imaginings (1), changes (5), susceptibility (21), fertilization (25) etc., these are now no longer describing actions; they are focused on objects or concepts. In nominalized expressions, the voice of the writing seems more abstract, objective and more formal. In each table, the probable congruent forms, types of processes and their frequency in per text in scientific texts are represented. As it was mentioned formerly, GM instances in these texts serve several important functions as the following examples: 
4.2.2 a. In order to explain hypothetically the break point, we can say that specialized sensors in the body observe those which are changing physiologically. (Congruent)

b. Hypothetical explanation for the break point is that specialized sensors in the body observe physiological changes ... (extracted from Scientific American). (GM)

Nominalization can turn a dynamic process (verbs) into a static entity through re-categorization and thus provides us with a different way of construing the world, or of conceptualizing experiences from a different angle. Once again, the above sentence (4.2.2.a) provides samples of congruent realization of meanings, whereby verbs encode actions (to explain, to change), while (4.2.2 b) provide metaphorical realization of meanings due to the fact that the actions of change and explain etc. are now nominalized and these actions or processes are rendered in concepts (nouns).

4.2.3 a. Foodborne disease has an enormous public health impact even if you count only the initial, acute episodes of illness. The Centers for disease control and prevention estimated in 2011 that the U.S. sees 48 million illnesses, 128,000 hospitalizations and 3,000 deaths every year from foodborne organisms. (GM)

b. The illness caused by food is enormously effective on public health even if you count only the initial, acute episodic aspects of those who are ill. The centers to control and prevent disease has estimated in 2011 that the U.S sees millions of people who are ill, 128,000 who are hospitalized and 3,000 who die every year from foodborne organisms. (Congruent)

In the above example, the processes (verbs) (hospitalize, die, control and prevent) are metaphorically coded as nouns (hospitalization, death, control and prevention) and properties (adjectives) (effective, episodic, and ill) are reworded as nouns as well (impact, episodes and illness). It is worth noting that Nominalization, as a form of GM, allows a large amount of information to be packed into a comparatively small space such as, a noun group. By comparing the above instances (4.2.3a \& 4.2.3b), the eye-catching element is the length of the congruent example (4.2.3 b); it is too long, dull, informal and non-academic to some extent. The instance (4.2.3 a) is about 4 clauses; instead, in example $(4.2 .3 \mathrm{~b})$ there are ten clauses. The process of nominalization enables the writer to include more information in the same sentence, guarantee a better flow of discourse and add more beauty to the texts.

Eggins (1994) draws our attention to the fact that although heavily nominalized language can appear pretentious and noticeable and may make the meaning ambiguous, the real incentive for this grammatical process is a functional one: Nominalizations enables us to perform things with the passages that we are not able to do in non-nominalized texts. Nominalization allows us to get away from the dynamic and usually real word sequencing that goes with speaking, where we relate sequences of actions in which we featured as actors. By nominalizing actions and logical relations, we can organize our text not in terms of ourselves, but in terms of ideas, reasons, causes, etc (Eggins, 1994).

\subsection{Frequency of IGM Instances in Scientific Texts}

The frequency of process types in scientific genre is represented in table 5 and its following 


\section{Macrothink}

graphs as follows:

Table 5. Frequency \& percentage of Process types in Scientific Texts.

\begin{tabular}{|l|l|r|r|}
\hline \multicolumn{2}{|c|}{ Process types } & Frequency & Percent \\
\hline Valid & material & 280 & 50.2 \\
\cline { 2 - 4 } & relational & 181 & 32.4 \\
\cline { 2 - 4 } & mental & 31 & 5.6 \\
\cline { 2 - 4 } & verbal & 37 & 6.8 \\
\cline { 2 - 4 } & behavioral & 25 & 4.3 \\
\cline { 2 - 4 } & existential & 4 & .7 \\
\cline { 2 - 4 } & Total & 558 & 100.0 \\
\hline
\end{tabular}

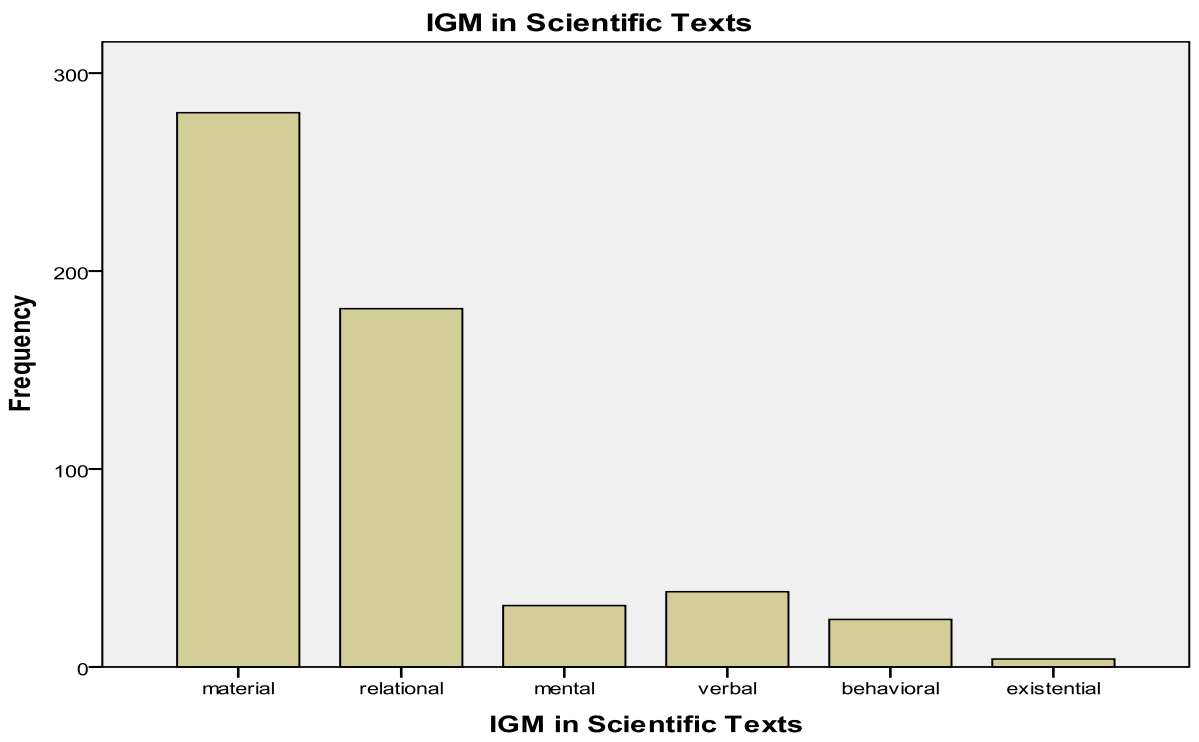

Figure 1. Frequency of process types in Scientific Texts

The above table and figure display the frequency and percentage of IGMs in scientific texts. 558 instances of IGM were extracted from ten scientific texts. 280 material, 181 relational, 31 mental, 37 verbal, 25 behavioural, 4 existential process types out of 558 were obtained. The scientific texts of the study represent the dominant textual forces of material (based on doing and happening) and then relational process types, based on being, having and description, than any other types.

\subsection{Discussion and Implications}

Referring to the research questions posed in the study, the discussion of the findings is illustrated as follows and they confirm Halliday and Matthiessen's (2004) suggestion that the ideational grammatical or transitivity analysis should show dominance of a material type process. 
As it was indicated above, GM has its unique recurring properties as a kind of grammar phenomenon in the scientific texts. The congruence and metaphor are two means to express the meaning; thus, they are regarded as different choices of grammatical structures. If semantic/lexical metaphor is defined as the substitution of one word by another, GM may be defined as "a substitution of one grammatical class, or one grammatical structure, by another" (Halliday \& Martin, 1993, p. 79), and GM is conceived as an incongruent realization of a given semantic configuration in the lexico-grammar (Halliday, 1985, 1994). The systemic-functional perspective on nominalizations is closely related to the concept of GM; nominalization is introduced as the resource for the creation of GM. To Halliday, metaphorization of the processes leads to the nominalization. Nominalization, to put in Halliday's terms (1994, p. 352), is "the single most powerful resource for creating GM". Thus, Nominalization can be defined as the process by which congruent elements are rendered in to function as non-congruent ones.

To Halliday (1994), IGM is a non-congruent realization of the ideational meaning. It is principally depicted by the transitivity system. In the English transitivity system, there are 6 main types of process: material, mental, relational, behavioral, verbal and existential processes, and these can be found in the grammatical categories. A process consists, in principle, of three components: "(1) the process itself; (2) participants in the process; and (3) circumstances associated with the process" (Halliday, 1994, p. 107). The shifts can be between the processes or a transition of participants and circumstances and this is what Halliday calls GM. These provide the frame of reference for interpreting our experience of what goes-on.

Comparing the metaphorical and congruent domains of this study indicates the paramount importance of GM, and without it, the scientists and scientific texts writers will fail to convey their intended meanings and outlooks to the reader. Nominalization reduces the number of clauses to make more information be compressed and packed into each nominal group which enables an academic and scientific writer to concisely and precisely refer to recurring abstract ideas, a single sentence to encapsulate in several complex abstract ideas. The study of the utilizations of GM is particularly helpful in disclosing how processes are rendered in concepts, thus modifying not only the grammar of texts but also reader responses to the texts. By nominalizing and packing information, GM is a very economical method of encapsulating information and; as a consequent, its occurrence is significantly noticeable in scientific and technical registers.

In all metaphoric instances of the study, the real doers are often absent from the surface structure, switched by the nominalizations. GM, thus, symbolizes an appearance of objectivity, abstractness, technicality, rationality and of course obscurity to the scientific texts. The results of the study indicates that utilizing nominalization in the above texts allows information packaging, building up chains of reasoning and rational arguments, continuing discussion on the topic, and creating technical and specialized terms and of course enabling an informationally dense discourse as well. It is worth mentioning that science is a field that involves defining, comparing, characterizing, classifying, and explaining, as well as building arguments for/against hypotheses made about, and the phenomena in the natural world. GM 
in general and nominalizations in particular are significantly right components for this objective.

The frequency and percentage of process types in scientific texts of the study and samples of IGMs are presented in tables 3, 4 and 5; they suggest that the most frequently used types of IGM in these texts are three types of GMs, i.e. 1, 2 and 9 (see table 2), being quality to entity (abundant to abundance), being process to entity (pollinate to pollination) and entity as modifier (drug resists to drug resistance) respectively. This finding supports Halliday's $(1985,1994)$ and Halliday and Matthiessen's $(1999$, 2004) emphasis on nominalization in English scientific discourse confirming that nominalization is the most omnipresent sort of GM in scientific registers and that the most dominant process type in transitivity analysis is material process, as in the result of the study.

Essentially, one of the main pedagogical implications of the present research and studies of the same nature is to smooth the path and supply a tool and outlook for scientific writings and those who tend to pursue IGM in their careers as scientific writers, students and researchers. Next, many students need the opportunity to learn how to read or probably how to write the scientific genres, so that they may effectively participate in scientific processes that this discourse is used for. Then, texts with a high degree of GM tend to be considered prestigious, abstract, objective, academic and formal in scientific contexts. Moreover, learning and knowing about GM and IGM can also shed light on the fluent and smooth process of translation to some extent, because translation requires students to possess high language ability and excellent command of English, such as GM and IGM. Furthermore, IGM helps students to reduce the number of clauses in their writing and compact more information into each nominal group. Therefore, it boosts the beauty of the clause and absorbs the reader's attention to pursue the writing. Eventually, when an action or a process is rendered in nominalization, much of the lexical meaning becomes lost or, rather, concealed, and obscurity often occurs. Nominalization can, therefore, create problems for readers, because it tends to obscure meanings and construct an ideology that is often not transparent to readers. Readers will have to discover the hidden meanings and resolve ambiguities in order to gain full understanding by learning GM and IGM respectively.

\section{Conclusion}

This study looked into a particular lexico-grammatical resource, the resource that SFL refers to as IGM. Proposed and evolved mainly by Halliday $(1985,1994)$, GMs can be identified in terms of the metafunctions. Simply put, In GM, actions are presented in a noun phrase; Activities or processes, which would naturally be expressed by verbs, become things. Nominalization is the prototypical instance of IGM. To Halliday and Matthiessen (2004), nominalization is developed first in scientific register, because of its massive potentiality and tendency for creating, devising, discovering and inventing new knowledge. Thus, from their point of view, nominalization serves the development of the sequential argument. Halliday and Martin (1993) and Vandenbergen et al. (2003) argue that the complexity of the scientific language is not also bound to the semantic level but it is also deeply affected by a range of particular grammar elements that construct discourse. Among the difficulties that scientific 
genre represent both to learners and researchers are technicality, lexical density and of course GM. Nominalization is one of the grammar structures causing a higher degree of lexical density and ambiguity and rationality in scientific texts.

In this study, the IGM framework was used to carry out an analysis on 10 scientific texts to pinpoint nominalization and process types. As it was shown, the main function of nominalization is people's removal. Studies based on GM in details are represented by scholars such as Halliday $(1985,1994)$ and Halliday and Martin (1993). From their point of view, GM under metafunctions of language in SFL is twofold: IGM and Interpersonal GM. The ideational function is to convey new information and to communicate a concept that is unknown to the hearer. In this process, the speaker is able to choose various ways to express his attitudes and worldview; the choice among the six processes in Halliday's transitivity system can generate IGM.

It was noticed that nominalization in scientific texts is strongly accompanied by definitions and clarifications; its function is to encapsulate meanings so that technical terms can be properly defined and elaborated. The occurrence of nominalization greatly increases the general information load the clause or the sentence states: the greater the number of included nominalizations, the greater the volume of the information, lexical density and of course obscurity, objectivity and abstractness expressed by the sentence. Thus GMs are fundamental, ideal for the scientific genre which places a premium on the conveyance of information in an economical and packed way. As stated by Halliday and Martin (1993) these are common components of scientific register.

As formerly stated, the main objective of this research was to discover nominalization and process types in 10 scientific texts. After analyzing metaphoric words and rendering them in congruent domain to distinguish the process types, it was observed that IGM has dominated scientific texts to some extent (558 IGMs). The analysis of the data depicted the prevailing utilization of material process type, based on action and doing, and then relational types, based on being and having. The three other processes (mental, verbal \& behavioral) are utilized with approximately the same numbers.

The analysis employed the theoretical model of Halliday \& Matthiessen (1999) which explores transitivity as a means of representing inner and outer world experiences. The purpose of using IGM in these texts is probably to render the lexis and grammar in the way the speaker or the writer wants and to generate or inform certain effects on his/her reader or audience. In each text, the goal is transmitting the intended meaning to the reader or the audience in a vivid, tempting and interesting way. In scientific, this is accomplished by several significant factors such as packing, encapsulation and devising technical, expert and specialized terminology that are readily accessible to a nimble conscious mind.

To Webster (2005b) and Halliday and Martin (1993), scientific genre enquires very high proportion of nominalizations. Thus, nominalizations are very essential in the creation of technicality enabling producing informationally dense structures. For this reason, nominalization was selected as a proper linguistic element for representing scientific texts and research articles. The present study has confined itself to fairly small scopes; however, 


\section{Macrothink}

International Journal of Linguistics ISSN 1948-5425 2013, Vol. 5, No. 4

the phenomenon of GM proved to open new possibilities up for investigating them in other types of discourses and with more numbers of texts.

\section{Acknowledgement}

The research is financed by Unique Language Centre (U. L. C.) located in Tabriz, Iran. I am grateful to Dr. Behnam, my supervisor, and Dr. Ghafoori, my reader, for not only allowing but encouraging me to pursue my interest in a linguistic theory and by their careful reading and helpful comments.

\section{References}

Aronoff, A., \& Miller, J. R. (2003). The handbook of linguistics. London: Blackwell Publishing. http://dx.doi.org/10.1002/9780470756409

Caffarel, A. (2006). A systemic functional grammar of French: From grammar to discourse. London/New York: Continuum.

Cehan, A. (2004). Language metafunctions in classroom discourse. Romanian Journal of English Studies, 4, 265-272.

Eggins, S. (1994). An introduction to systemic functional linguistics. London: Continuum.

Graber, P. L. (2001). Context in Text: A Systemic functional analysis of the Parable of the Sower. Georgia: Emory University Press.

Halliday, M. A. K. (1985). An Introduction to Functional Grammar (1st ed.). London: Edward Arnold.

Halliday, M. A. K. (1989). Spoken and written language. England: Oxford University Press.

Halliday, M. A. K. (1994). An introduction to functional grammar $\left(2^{\text {nd }}\right.$ ed.). London: Edward Arnold.

Halliday, M. A. K., \& Martin, J. R. (1993). Writing science. Literacy and discourse power. London: Flamer press.

Halliday, M. A. K., \& Matthiessen, C. M. I. M. (1999). Construing experience through meaning: A language-based approach to cognition. London/New York: Continuum.

Halliday, M. A. K., \& Matthiessen, C. M. I. M. (2004). An Introduction to Functional Grammar (3rd ed.). London: Edward Arnold.

Halliday, M. A. K., \& Webster, J. J. (2009). Continuum companion to systemic functional linguistics. London: Continuum.

Knowles, M., \& Moon, R. (2006). Introducing metaphor. New York: Routledge.

Martin, J. R., Matthiessen, C. M. I. M., \& Painter, C. (1997). Working with functional grammar. London: Edward Arnold.

Murar, I. (2004). On grammatical metaphor. Romanian Journal of English Studies, 4, 
115-123.

Rose, D. (1997). Science, technology and technical literacies. [Online] Available: http://www.readingtolearn.com.au/images/pdf/Science_technology_and_technical_literacies. pdf (March 15, 2012).

Taverniers, M. (2002). Systemic-functional linguistics and the notion of grammatical metaphor: A theoretical study and a proposal for a semiotic-functional integrative model. Belgium: University of Gent.

Taverniers, M. (2003). Grammatical metaphor in SFL: A historiography of the introduction and initial study of the term. [Online] Available: http://users.ugent.be/ mtaverni/publications.html (July 20, 2012).

Taverniers, M. (2006). Grammatical metaphor and lexical metaphor: Different perspectives on semantic variation. [Online] Available: http://users.ugent.be/ mtaverni/publications.html (June 25, 2012).

Thompson, G. (2004). Introducing functional grammar. London: Arnold.

Vandenbergen, S., Marie, A., Taverniers, M., \& Ravelli, L. (2003).Grammatical Metaphor: Views from systemic functional linguistics. Amsterdam: Benjamins.

Webster, J. J. (2003). On language and linguistics. London: Continuum.

Webster, J. J. (2005 a). Studies in English language. London/New York: Continuum.

Webster, J. J. (2005 b). Studies in Chinese language. University of Michigan: Continuum. 